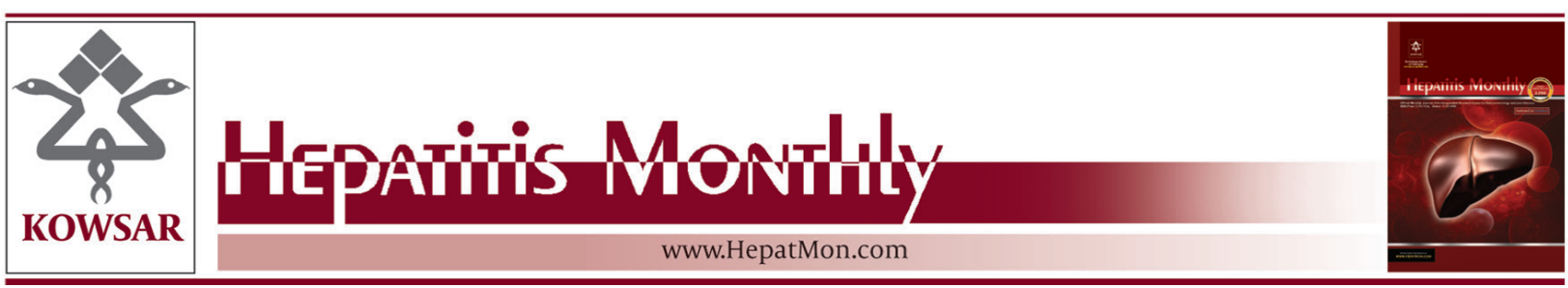

\title{
Histopathology of Post-Transplant Liver Biopsies, the First Report From Iran
}

\author{
Bita Geramizadeh ${ }^{1,2, *}$, Dorna Motevalli ${ }^{1}$, Saman Nikeghbalian ${ }^{3}$, Seyed Ali Malek Hosseini ${ }^{3}$ \\ ${ }^{1}$ Transplant Research Center, Shiraz University of Medical Sciences, Shiraz, IR Iran \\ ${ }^{2}$ Department of Pathology, Shiraz University of Medical Sciences, Shiraz, IR Iran \\ ${ }^{3}$ Department of Surgery, Transplant Center, Shiraz University of Medical Sciences, Shiraz, IR Iran \\ *Corresponding author: Bita Geramizadeh, Department of Pathology, Shiraz University of Medical Sciences, 71345-1864 Shiraz, IR Iran. Tel: +98-7116474331, \\ Fax:+98-7116474331, E-mail: geramib@susma.c.ir.
}

\section{A B S T R A C T}

Background: Evaluation of a transplanted liver by Imaging techniques and enzyme changes is sensitive to hepatocellular or biliary problems, but in most instances liver allograft biopsies are performed in order to find out the final reason for these changes.

Objectives: It's been about 17 years (with more than 1326 cases) since the first liver transplantation in the Namazi Hospital of Shiraz University of Medical Sciences while during the last five years the number of post liver transplant biopsies have increased. Until now there has been no report of the pathological results of post liver transplant needle biopsies from Iran.

Materials and Methods: During the last 5 years, there have been 382 post liver transplant biopsies. We studied the clinical charts and pathological results of all needle biopsies.

Results: A total of 382 needle biopsies were performed on 287 patients aged between 1 and 64 years old. The earliest specimen was obtained within the first few hours following transplantation, and the last was gathered 3209 days (261 \pm 523$)$ post-transplantation. Acute rejection was the most common diagnosis, which occurred in 180 (47\%) of specimens. Among other complications were vascular problems (8.6\%), preservation/reperfusion (I/R) injury (7\%), chronic rejection(5.2\%), biliary injury/obstruction (3.4\%), recurrence of primary disease (2.6\%), druginduced hepatic injury (1.8\%), cirrhosis (1.6\%), sepsis (1.4\%), cytomegalovirus hepatitis (1.4\%), post-transplantation lymphoproliferative disease (1\%) and Venous outflow obstruction (0.5\%).

Conclusions: The most common pathological diagnosis of post-transplant liver needle biopsies has been acute rejection, followed by ischemia due to hepatic artery thrombosis, preservation/reperfusion injury, and chronic rejection.

Keywords: Liver Transplantation; Biopsy; Iran

Copyright ( @ 2013, Kowsar Corp.; Published by Kowsar Corp.

Article type: Research Article; Received: 01 Dec 2012; Revised: 07 Jan 2013; Accepted: 18 Feb 2013; Epub: 18 Jun 2013

Implication for health policy/practice/research/medical education:

This manuscript will help people working with liver transplant patients to understand the reason behind their abnormal enzymes.

Please cite this paper as:

Geramizadeh B, Motevalli D, Nikeghbalian S, Malek Hosseini SA. Histopathology of Post-Transplant Liver Biopsies, the First Report From Iran. Hepat Mon. 2013;13(6):e9389. DOI:10.5812/hepatmon.9389 


\section{Background}

Liver transplantation has been accepted as the main therapeutic option for patients with end-stage liver diseases (1). Monitoring of the transplanted liver by Imaging techniques and enzyme changes are sensitive to hepatocellular or biliary injuries and problems, but in most cases, liver allograft biopsies are performed in order to find out the reason for these changes $(2,3)$. Therefore, in many instances liver histology remains the "gold standard" for the diagnosis of allograft dysfunction (4). The following is a review of pathology in 382 needle biopsies of 287 liver allograft recipients. This is the first report of post liver transplant biopsies from Iran.

\section{Objectives}

It's been about 17 years (with more than 1326 cases) since the first liver transplantation in the Namazi Hospital of Shiraz University of Medical Sciences while during the last five years the number of post liver transplant biopsies have increased. Until now there has been no report of the pathological results of post liver transplant needle biopsies from Iran. Therefore in this study we are trying to present our experience regarding the results of post liver transplantation biopsies in our center as the largest center in Iran.

\section{Materials and Methods}

This study was conducted from December 2005 to January 2011 in the Department of Pathology, Namazi Hospital, Shiraz, Iran. Information including age, reason for transplantation, date of biopsies and the pathological report including the main cause of graft injury were collected, using pathology files and patients' clinical charts. All patients undergoing needle biopsies post-transplantation in our center were considered for the study. A total of 382 needle Biopsies were obtained from 287 patients, few hours to 3209 days after transplantation. Blind or Ultra-sound guided liver needle biopsy was obtained. Specimens were fixed in 10 \% buffered formaldehyde and embedded in paraffin. Seven consecutive sections were cut at a thickness of 3 micrometers from paraffin-embedded biopsies. Biopsy sections were stained by hematoxylin-eosin (H\&E) methods, Masson's trichrom, reticulin, periodic acid-Schiff with diastase, prussian blue, orcein and again with $\mathrm{H} \& \mathrm{E}$. Immunohistochemical studies were done if needed such as CK19 (Cytokeratin 19), CMV (Cytomegalovirus), HBV (Hepatitis B virus), and EBV (Epstein Barr virus). The following features were evaluated in liver biopsies:

1) Number of portal tracts and adequacy of the biopsy (Biopsies with at least 5 portal tracts were considered adequate).

2) Architecture of the liver (both lobular and vascular)

3) Presence of any pathology including acute and chron- ic rejections, infection, malignancies, etc.

Grading of the disease accordingly, for example for acute rejection grading was made based on the BANFF 1997 (5) criteria. Criteria for evaluating chronic rejection was based on Banff Schema published in 2000 (6). Statistical Analysis was performed by using Microsoft Excel software for Windows.

\section{Results}

During the study period (2005-2011) a total of 382 indicated needle biopsies were obtained from 287 patients. The age of the patients was $1-64$ years $(28.6 \pm 16.36)$. The most common indication of transplantation in our center was Hepatitis B (20.2\%), however less common causes were autoimmune hepatitis, primary sclerosing cholangitis etc. In this study, the earliest specimen was obtained within a few hours following transplantation, and the latest was gathered 3209 days $(261 \pm 523)$ days post-transplantation (Table 1). These cases were among the 1326 liver transplants performed during the past 17 years (Table 2). Acute rejection was the most common diagnosis; 180 (47\%) of 382 liver biopsies were in favor of acute rejection. Ischemic changes, including mild ischemia to severe zone 3 necrosis and complete coagulative necrosis occurred in 33 liver biopsies among this group, these changes were detected from 0 to 2676 days posttransplantation $(163 \pm 498.9)$. The cause of these ischemic changes was hepatic artery thrombosis. Preservation/reperfusion injury were mostly detected soon after transplantation, which ranged from 0 to 17 days (6.1 \pm 5.5 ) following transplantation in $8.6 \%$ of biopsies (Figure 1). Chronic Rejection (CR) mainly occurred late in the posttransplantation period. In Our study CR was detected in 20 (5.2\%) of the liver biopsies and time of occurrence was from 90 to 3128 days after transplantation (88.7 \pm 865 ) (Figure 2). Large bile duct obstruction was diagnosed in 13 (3.4\%) specimens from 0 to 17 days (45.2 $\pm 58.6 \%)$. Recurrence of hepatitis happened in 10 cases (2.6\%) during 233 to 1257 days following transplantation. Of these cases, 3 patients were diagnosed with hepatitis $B$ and in the remaining 7 patients, recurrent hepatitis $C$ was diagnosed. All of the hepatitis B recurrences were among the patients who had not received immunoglobulin and antiviral agents properly. All of the 3 cases of recurrent hepatitis $B$ were confirmed by immunohistochemistry with surface antigen (HBS Antigen) and viral load (Figure 3). Cases suspicious to recurrent hepatitis $\mathrm{C}$ were also confirmed by viral load. The incidence of cirrhosis was $1.6 \%$ in allograft biopsies, which occurred in 6 patients, from 390 to 3126 days post-transplantation (1200 \pm 929.8$)$. These six cases were patients with previous diagnosis of autoimmune hepatitis (3 patients) and hepatitis C related cirrhosis (3 patients). Post-transplant lymphoproliferative disorder (PTLD) had also been diagnosed in allografted liver of 4 patients as part of a systemic disease or as a primary site 
of involvement (Figure 4). Drug-induced cholestasis due to antibiotics such as sulfamethoxazole-trometoprime and amoxicillin were also detected in 7 patients after liv- er transplantation. Other rare diagnoses were infections due different viral agents such as CMV and tuberculosis.

Table 1. Frequency and Timing of Different Histopathologic Findings in 382 Patients

\begin{tabular}{|c|c|c|c|c|c|}
\hline Diagnosis & Biopsies, No. (\%) & Mean Days & SD & $\begin{array}{l}\text { Minimum days post- } \\
\text { Transplant }\end{array}$ & $\begin{array}{l}\text { Maximum days post- } \\
\text { Transplant }\end{array}$ \\
\hline \multicolumn{6}{|l|}{ Acute Rejection } \\
\hline Borderline $\left(\mathrm{RAI}^{\mathrm{a}}=1\right)$ & $10(2.6)$ & 346.4 & 418.0 & 12 & 1351 \\
\hline $\operatorname{Mild}(\mathrm{RAI}=2,3)$ & $93(24.3)$ & 148.3 & 360.2 & 0 & 2210 \\
\hline $\begin{array}{l}\text { Moderate }(\mathrm{RAI}=4, \\
5,6)\end{array}$ & $33(8.6)$ & 326.1 & 650.4 & 0 & 3209 \\
\hline Severe $(\mathrm{RAI}=7,8,9)$ & $44(11.5)$ & 310.5 & 524.3 & 0 & 2616 \\
\hline $\begin{array}{l}\text { Ischemic changes (He- } \\
\text { patic artery thrombosis) }\end{array}$ & $33(8.6)$ & 163.0 & 498.9 & 0 & 2676 \\
\hline $\begin{array}{l}\text { Preservation/reperfusion } \\
\text { injury }\end{array}$ & $27(7)$ & 6.1 & 5.5 & 0 & 17 \\
\hline Chronic rejection & $20(5.2)$ & 887.7 & 865.0 & 90 & 3128 \\
\hline biliary obstruction & $13(3.4)$ & 45.2 & 58.6 & 0 & 176 \\
\hline $\begin{array}{l}\text { Recurrence of primary } \\
\text { disease }\end{array}$ & $10(2.6)$ & 672.8 & 349.6 & 233 & 1257 \\
\hline Drug induced cholestasis & $7(1.8)$ & 229.4 & 237.6 & 14 & 690 \\
\hline Post liver $\mathrm{Tx}^{\mathrm{a}}$ cirrhosis & $6(1.6)$ & 1200 & 929.8 & 390 & 3126 \\
\hline Sepsis & $5(1.4)$ & 111.8 & 136.3 & 3 & 364 \\
\hline $\mathrm{CMV}^{\mathrm{a}}$ Hepatitis & $5(1.4)$ & 23.4 & 12.5 & 7 & 43 \\
\hline PTLD $^{\mathrm{a}}$ in allograft liver & $4(1)$ & 715 & 594.7 & 171 & 1700 \\
\hline $\begin{array}{l}\text { Venous Outflow obstruc- } \\
\text { tion }\end{array}$ & $2(0.5)$ & 1.5 & & 1 & 2 \\
\hline $\mathrm{TB}^{\mathrm{a}}$ in allografted liver & $1(0.26)$ & 1818 & & & \\
\hline Suboptimal & $2(0.5)$ & & & & \\
\hline Normal pathology & $67(17.74)$ & & & & \\
\hline
\end{tabular}

a Abbreviations: RAI, Rejection activity index; PTLD, Post-transplant lymphoproliferaive Disorder; TX, transplant; TB, Tuberculosis

Table 2. The Causes of Liver Transplantations, Performed Before January 2012 in Shiraz Transplant Center Among 1326 Patients

\begin{tabular}{lll}
\hline Cause of Transplant & Number & Percentage, \% \\
\hline Hepatitis B & 290 & 21.8 \\
\hline Autoimmune hepatitis & 235 & 17.7 \\
\hline Primary Sclerosing cholangitis & 150 & 11.5 \\
\hline Wilson & 115 & 6.7 \\
\hline Biliary atresia & 60 & 5.6 \\
\hline Tyrosinemia & 40 & 3 \\
\hline Hepatitis C & 40 & 3 \\
\hline Progressive familial intrahepatic cholestasis & 40 & 3 \\
\hline Primary biliary cirrhosis & 18 & 1.5 \\
\hline Budd-Chiari & 30 & 2.4 \\
\hline Crigler-Najjar & 30 & 2.4 \\
\hline Hypercholestrolemia & 25 & 2 \\
\hline
\end{tabular}




\begin{tabular}{lll} 
Alcoholic & 15 & 1.5 \\
\hline Neonatal hepatitis & 9 & 0.6 \\
\hline Acute liver failure & 6 & 0.45 \\
\hline Caroli & 5 & 0.4 \\
\hline Hyperoxaluria & 3 & 0.3 \\
\hline Congenital hepatic fibrosis & 4 & 0.3 \\
\hline Neoplastic & 11 & 0.8 \\
\hline Cryptogenic (NASH) & 200 & 15 \\
\hline
\end{tabular}

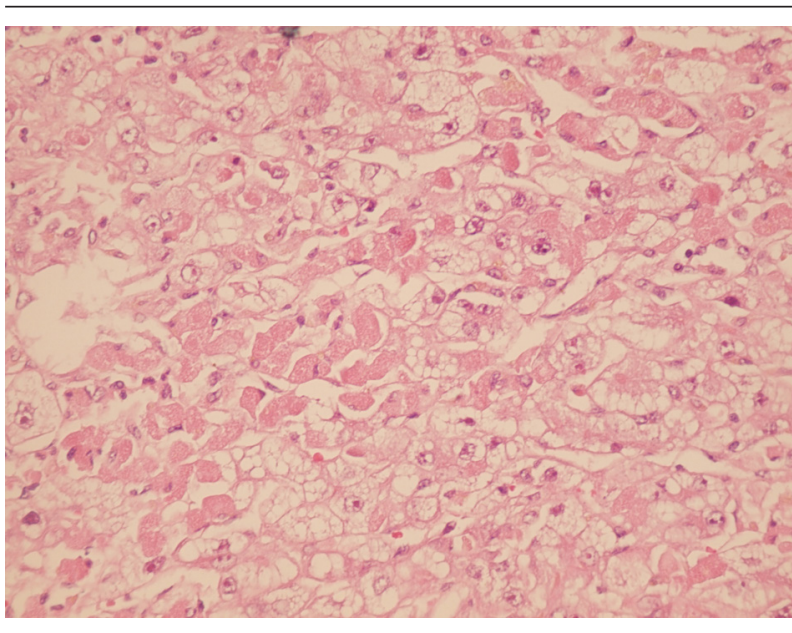

Figure 1. Sections From Liver Needle Biopsy Show Pericentral Ballooning Degeneration and Single Cell Apoptosis, 7 Days Post Transplantation (H\&E $\mathrm{X} 250$ )

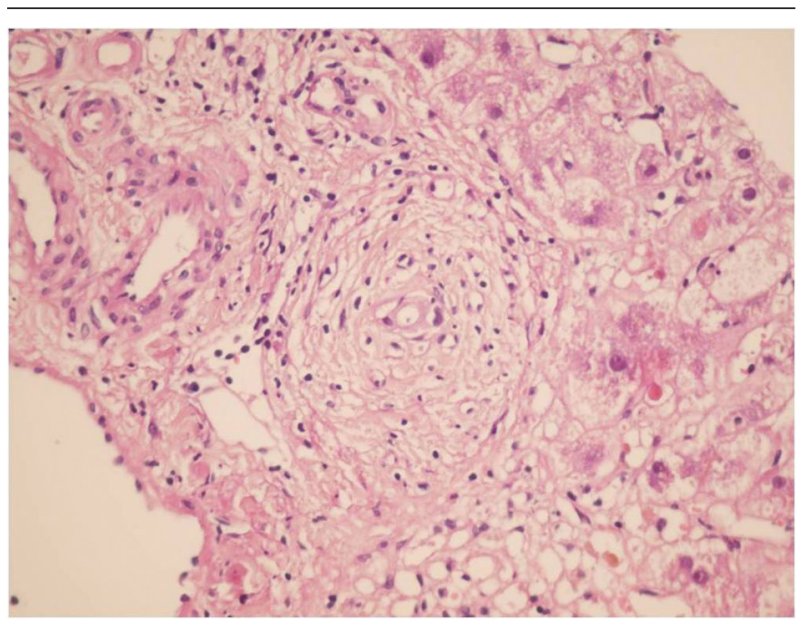

Figure 2. Sections From Liver Needle Biopsy Show Marked Bile Duct Epithelial Damage, 3 Months Post Transplantation, Which is considered as Early Chronic Rejection (H\&EX250)

\section{Discussion}

Liver allograft pathology continues to play an important role in the diagnosis and management of complications in the course of liver transplantation. Liver needle biopsy is a convenient method for monitoring allograft complications (7). Histopathological assessments continue to play an important role in the diagnosis and management of liver allograft rejection. Changes that occur in acute and chronic rejection are well recognized and liver biopsy remains the "gold Standard" for diagnosing these two conditions (8). In our study the most common histopathological finding in post liver transplant biopsies was acute rejection occurring in $46 \%$ of the cases, most of which were mild acute rejection i.e. RAI (rejection activity index) was below 3 . This finding was similar to that reported by previous studies $(9,10)$. Acute rejection occurring after 6 months from transplantation has been termed, late acute rejection by some authors (8). We had the same experience with acute rejections, 6 months post transplantation where the histological features of rejection had changed with time. The gold standard for the diagnosis of chronic rejection is also based on liver biopsy findings, and the incidence of this condition has been reported to be between 2 and $20 \%(2,8)$.

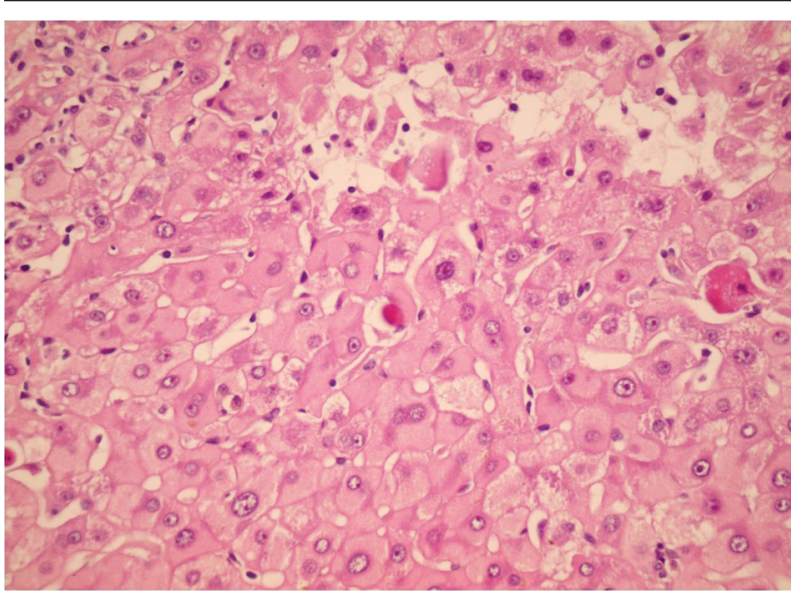

Figure 3. Sections From Liver Needle Biopsy in a Recurrent Chronic Hepatitis B Shows Ground Glass Hepatocytes (H\&E X250)

According to our experience, the incidence of chronic rejection in our center was about $5.2 \%$, and we had chronic rejections as early as 3 months post liver transplantation. More time is required to decide the exact rate of chronic rejection in our center. The other major concern in $7 \%$ of our cases was preservation/reperfusion injury in the first 2 weeks post liver transplantation using deceased donors' livers. In other studies this condition has been 
reported in about $13.4 \%$ of transplanted livers (9).
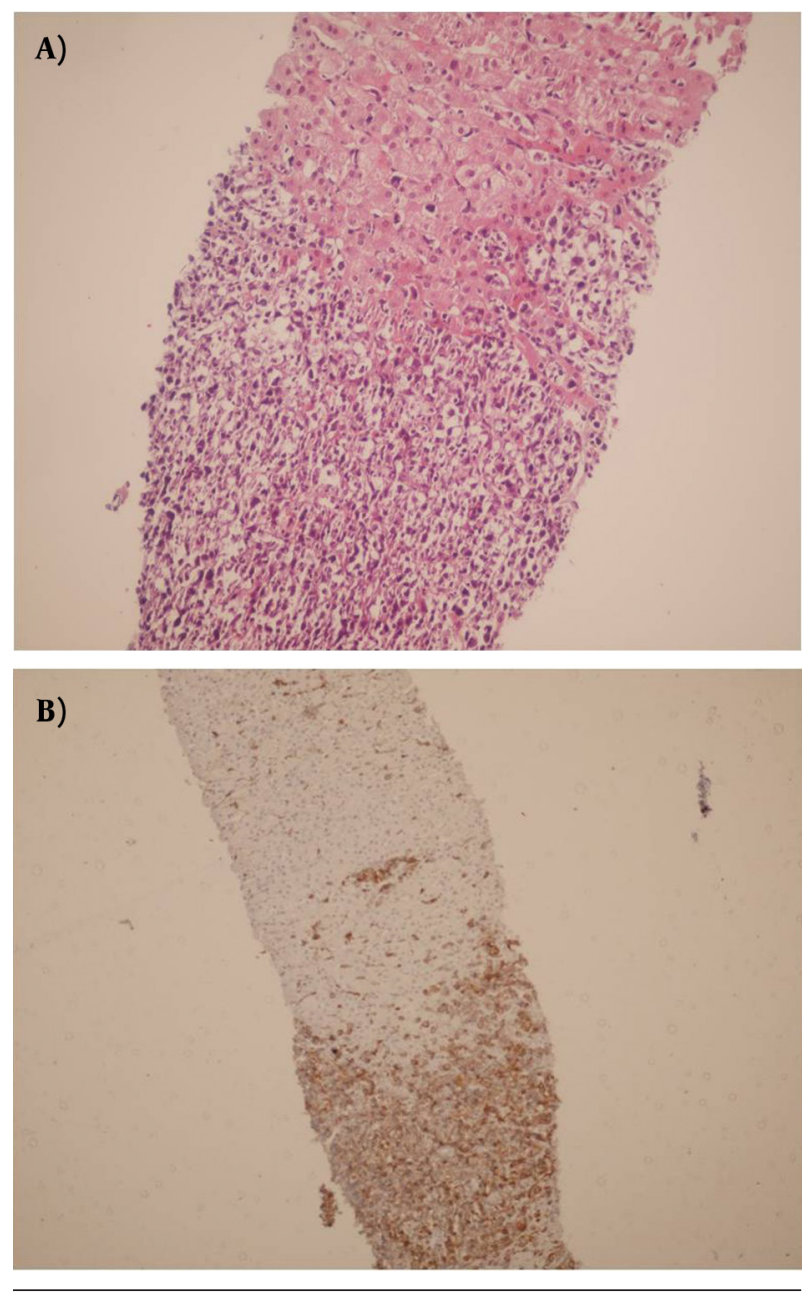

Figure 4. Sections From Allografted Biopsy Shows Dense Infiltration of Lymphoma Cells, Diagnosed as PTLD (A and B) (a: H\&EX250, b:IHC for CD20 )

Our results showed better preservation and less hepatic damage during cold and warm ischemic times. Post liver transplantation fibrosis, and cirrhosis have been reported in previous studies in 10-30\% of liver transplant patients, mostly in the patients with underlying chronic hepatitis such as hepatitis $C$ and autoimmune hepatitis related cirrhosis as early as 18 months $(11,12)$. This was much less in our experience i.e. we had post liver transplant cirrhosis in only 6 patients $(1.6 \%)$ and as early as 15 months in a patient who had been transplanted due to hepatitis $\mathrm{C}$ related cirrhosis. The lower incidence of post liver transplant cirrhosis might be because of shorter duration of follow up in our patients (it is only 17 years after the first liver transplant in our center) and also less hepatitis C related cirrhosis in our transplanted patients compared with western countries. Hepatic artery thrombosis and different degrees of ischemic hepatocyte necrosis in our cases have been present in $8.6 \%$ of post liver transplant biopsies. This incidence in previous reports has been 1.6 to $10.5 \%$, as early as less than one hour post transplantation $(13,14)$. Long-term survival after liver transplantation due to improvements in surgical techniques, and immunosuppressive regimens, has increased the recurrence rate of the primary diseases. The frequency of recurrence depends on the etiology and the primary liver disease (2). Regarding the recurrence of hepatitis B, currently combination therapy of oral antiviral agents and hepatitis B immunoglobulin in the pre and post-transplant period has achieved complete protection (15). However, there were 3 patients with recurrent hepatitis B in our study, because the patients hadn't received their regimen properly due to incompliance. The remaining recurrent diseases were HCV chronic hepatitis. According to infectious diseases, we've had rare CMV hepatitis involving allografted livers. CMV hepatitis is a significant complication after liver transplantation and has a reported incidence of $2-10 \%$ (16). In the period of this study we experienced 5 cases of CMV hepatitis documented by liver biopsy, which were confirmed by immunohistochemistry. We had an unusual case of post liver transplant tuberculosis with the isolated involvement of the allografted liver which was treated successfully and has been described in details in another paper in press (17). Post-transplant lymphoproliferative disorder (PTLD) has been diagnosed in 4 cases of allografted livers. Diagnosis of PTLD in the allografted liver is not common and can be part of a pre-existing PTLD, but rarely can be the primary manifestation of the disease (18). In this series of transplanted patients, two PTLD of the allografted liver were primary and in another two liver involvement was part of the systemic disease (19). We diagnosed 7 cases with drug-induced cholestasis. In the majority, antibiotics such as amoxicillin and sulfamethoxazole were considered as the probable cause and discontinuation resulted in recovery and this has been reported by previous studies $(20,21)$. We had a case of cholestasis and severe pruritis about 2 years post transplantation after use of anabolic steroid for body-building in a patient with previous diagnosis of primary sclerosing cholangitis; the patient's condition improved with discontinuation of the drug. Technical complications such as biliary stricture of the anastomosis site and vascular complications have also been rarely diagnosed in our patients during the last 5 years. In conclusion, our hospital is the main liver transplant center in Iran and also the majority of post-transplant liver biopsies are performing here (It is worthy to note that nearly all liver biopsies taken outside of our center are reviewed as a consult case and has been included in this study), thus we have experienced all the reported complications resulting from liver biopsies.

\section{Acknowledgements}


We would like to acknowledge the pathology staff of Namazi hopsital for their great help regarding the preparation of liver biopsies.

\section{Author's Contribution}

Each about 30-50\%.

\section{Financial Disclosure}

There is no financial disclosure.

\section{Funding/Support}

There is no funding/support.

\section{References}

1. Yu YY, Ji J, Zhou GW, Shen BY, Chen H, Yan JQ, et al. Liver biopsy in evaluation of complications following liver transplantation. World J Gastroenterol. 2004;10(11):1678-81.

2. Adeyi O, Fischer SE, Guindi M. Liver allograft pathology: approach to interpretation of needle biopsies with clinicopathological correlation.J Clin Pathol. 2010;63(1):47-74.

3. Gao ZH. Seeking beyond rejection: an update on the differential diagnosis and a practical approach to liver allograft biopsy interpretation. Adv Anat Pathol. 2009;16(2):97-117.

4. Portmann B. Liver allograft pathology and biopsy interpretation. Verh Dtsch Ges Pathol. 2004;88:29-38.

5. Banff schema for grading liver allograft rejection: an international consensus document. Hepatology. 1997;25(3):658-63.

6. Demetris A, Adams D, Bellamy C, Blakolmer K, Clouston A, Dhillon AP, et al. Update of the International Banff Schema for Liver Allograft Rejection: working recommendations for the histopathologic staging and reporting of chronic rejection. An International Panel. Hepatology. 2000;31(3):792-9.

7. Drebber U, Torbenson M, Wedemeyer I, Dienes HP. [Current aspects of liver allograft pathology]. Pathologe. 2011;32(2):113-23.

8. Neil DA, Hubscher SG. Current views on rejection pathology in liver transplantation. Transpl Int. 2010;23(10):971-83.

9. Cong WM, Zhang SY, Wang ZL, Xue L, Liu YS, Zhang SH. [Pathologic diagnosis of 1123 post-transplant liver biopsies from 665 liver transplant patients]. Zhonghua Bing Li Xue Za Zhi. 2005;34(11):716-
10. Gornicka B, Ziarkiewicz-Wroblewska B, Bogdanska M, Oldakowska-Jedynak U, Wroblewski T, Morton M, et al. Pathomorphological features of acute rejection in patients after orthotopic liver transplantation: own experience. Transplant Proc. 2006;38(1):221

11. Calvaruso V, Dhillon AP, Tsochatzis E, Manousou P, Grillo F, Germani G, et al. Liver collagen proportionate area predicts decompensation in patients with recurrent hepatitis $\mathrm{C}$ virus cirrhosis after liver transplantation. J Gastroenterol Hepatol. 2012;27(7):1227-32.

12. Guido M, Fagiuoli S, Tessari G, Burra P, Leandro G, Boccagni P, et al. Histology predicts cirrhotic evolution of post transplant hepatitis C. Gut. 2002;50(5):697-700.

13. Bekker J, Ploem S, de Jong KP. Early hepatic artery thrombosis after liver transplantation: a systematic review of the incidence, outcome and risk factors. Am J Transplant. 2009;9(4):746-57.

14. Proposito D, Loinaz Segurola C, Garcia Garcia I, Jimenez C, Gonzalez Pinto I, Gomez Sanz R, et al. [Assessment of risk factors in the incidence of hepatic artery thrombosis in a consecutive series of 687 liver transplantations]. Ann Ital Chir. 2001;72(2):187-205.

15. Yilmaz N, Shiffman ML, Todd Stravitz R, Sterling RK, Luketic VA Sanyal AJ, et al. Prophylaxsis against recurrance of hepatitis B virus after liver transplantation: a retrospective analysis spanning 20 years. Liver Int. 2008;28(1):72-8

16. Seehofer D, Rayes N, Neumann UP, Meisel H, Oettle H, Nussler NC, et al. Changing impact of cytomegalovirus in liver transplantation - a single centre experience of more than 1000 transplantations without ganciclovir prophylaxis. Transpl Int. 2005;18(8):941-

17. Geramizadeh B, Nikeghbalian S, Janghorban P, Malekhosseini SA Isolated Tuberculosis of Transplanted Liver, A Case Report and Review of the Literature. Hepat Mon. 2013;13(5):e6691.

18. Izadi M, Taheri S. Features, predictors and prognosis of lymphoproliferative disorders post-liver transplantation regarding disease presentation time: report from the PTLD.Int. survey. Ann Transplant. 2011;16(1):39-47.

19. Geramizadeh B, S. N, Dehghani SM, Bahador A, Salahi H, MalekHosseini SA. Primary Involvement of allografted liver in PostTransplant Lymphoproliferative Disorders, Report of Two Pediatric cases and Review of the Literature. IRCMJ. 2012;14(11):724-6.

20. Mohi-ud-din R, Lewis JH. Drug- and chemical-induced cholestasis. Clin Liver Dis. 2004;8(1):95-132, vii.

21. Studniarz M, Czubkowski P, Cielecka-Kuszyk J, Jankowska Teisseyre M, Kaminska D, et al. Amoxicillin/clavulanic acid-induced cholestatic liver injury after pediatric liver transplantation. Ann Transplant. 2012;17(1):128-31. 